\title{
Incorporating social context and co-evolution in an innovation diffusion model-with an application to cleaner vehicles
}

\author{
Marc Dijk • René Kemp • Pieter Valkering
}

Published online: 31 August 2011

(C) The Author(s) 2011. This article is published with open access at Springerlink.com

\begin{abstract}
Existing diffusion models have proven less suitable for the analysis of environmental innovations, such as hybrid vehicles, which emerge in a context of changing social appraisal and regulatory support. In this paper, we offer an agent-based analysis of innovation diffusion which is better suitable for those cases. We explore future scenarios of car engine technology with support of a simulation model. In the model, actor behavior is modeled explicitly on the basis of actor frames and the consequent appraisal of technology options by potential adopters and by suppliers. The model is analytically novel in that it incorporates five feedback loops: interactive learning between suppliers and users, scale and learning economies, endogenous taste formation among consumers, and social learning (attribution of meaning). In the model, consumer decisions influence each other and the supply of innovation by shaping R\&D and investment decisions of suppliers. The model is applied to explore future diffusion scenarios of clean vehicles, though it starts with simulating recent historic trends, including the quick diffusion of direct fuel injection systems and slow diffusion of electric vehicles in the last 20 years. It is shown that the success of hybrid electric vehicles critically depends on suppliers shifting towards HEV development and production (resulting in greater supply of HEV models) and on consumers valuing hybrid electric vehicles more than environmentally improved diesel vehicles.
\end{abstract}

Keywords Innovation - Diffusion - Conceptual model - Simulation • Co-evolution $\cdot$ Cleaner cars

JEL Classification $\mathrm{O} 31 \cdot \mathrm{O} 33$

M. Dijk (凶) · R. Kemp · P. Valkering

ICIS, Maastricht, The Netherlands

e-mail:m.dijk@maastrichtuniversity.nl 


\section{Introduction}

Many diffusion models have been developed in the last decades, based on various assumptions as to the mechanism behind them. The best known and most popular model is the epidemic model (pioneered by Bass 1969), where diffusion is governed by epidemic learning. A second type of model is the rational choice or threshold model (David 1969; Kemp 1998). In this type of model, individual decisions are modeled. Both models are widely and successfully applied to simple as well as to complex technologies, varying from lead free petrol to wastewater treatment technologies. There has emerged a third type of diffusion model that incorporates endogenous technological change, called the evolutionary or 'non-equilibrium' model (in the tradition of Nelson and Winter 1982). This type of model includes (random) events and learning, which result in changes in the techno-economic characteristics of the technologies. Recently, some models of this type incorporated evolution of consumers, referred to as co-evolutionary modeling (Windrum and Birchenhall 2005; Windrum et al. 2009a, b).

Although existing diffusion models have shown their value in simulating innovation at the firm level (technological innovation, learning), the market and sector level (competition and diffusion, structural change), and the macro level (growth, long waves and international trade), the models are as yet less applied to consumer products in a changing social context. Popularity or social connotation of products, especially new emerging environmental products, may change alongside technological innovation. A chief example is the hybridelectric vehicle, which entered the car market around 2000. Owners see their vehicle as 'socially responsible', as 'the right vehicle for society' (Heffner et al. 2006). Progression of such connotation will influence the further innovation and diffusion process of the technology, affecting both the consumer and the producer side. There are currently no models available that incorporate this interaction of such social and technological aspects.

In this paper, we aim to extend the co-evolutionary approach to innovation diffusion in a changing social context. To this end, we incorporate elements of the literature of social construction of technology (SCOT; Bijker 1995) into an evolutionary model. This results in an agent-based model to analyze the interaction between consumer demand and industry supply as a co-evolutionary process. Agents' behavior is subject to feedback mechanisms from microto-micro, as well as macro-to-micro. One such mechanism is the creation of meaning by consumers of a product based on product characteristics. By attaching weights to various product attributes, different groups of consumers interpret the same product differently: they attach different meaning and value to it. The set of weights that an actor group applies in evaluating adoption and investment is called a frame. A potential adopter's frame includes attributes of functionality, but also of social connotation. The attribution of meaning (especially by early adopters) influences other consumers' decisions, something that is well-established in marketing but has been neglected in innovation diffusion analysis. The interplay of demand and supply through various feedback loops 
give rise to trajectories. These paths of innovation may be modeled on the basis of the feedback loops. This will be done here for the example of car engines.

The paper offers a bridge between two literatures: innovation diffusion and social construction of technology (SCOT; Bijker 1995), dealing with shortcomings of both literatures, such as the assumption of an objective innovation in the innovation literature and the neglect of techno-economic characteristics of the innovation and co-evolution processes in the SCOT literature.

This paper has five sections. In Section 2, we review the diffusion modeling literature, covering the early epidemic modeling approach of Bass, up to the recent co-evolutionary approach. In Section 3, we describe our model concept, offering a richer conceptualization than current diffusion models, in particular by drawing from the literature on the social construction of technology (SCOT; Bijker 1995). In Section 4, we describe a simulation model that formalizes the modeling concept for the case of car engine innovation. In Section 5, the model is applied and two model runs are discussed with a focus on the role of social connotation. Section 6 presents scenarios for the future diffusion of cleaner car engines, supported by the model runs. Section 7 draws conclusions and discusses the novelties of our analysis and challenges for future research.

\section{Understanding innovation diffusion: from epidemic modelling towards a co-evolutionary approach}

Much has been written about innovation diffusion. The focus is typically on aggregate patterns. Rogers (1995) mentions five characteristics of an innovation, as perceived by potential adopters, which help to explain their difference in rate of adoption: (1) relative advantage, (2) compatibility, (3) complexity, (4) triability, and (5) observability. He offers a typology of adopters based on when they adopt but does not offer a dynamic model of innovation diffusion in terms of endogenous and exogenous mechanisms.

For explaining dynamic patterns, we have three types of models. The first, most well-known, and widely applied model is the epidemic model pioneered by Bass (1969). It builds on the premise that what limits the speed of usage is the lack of information available about the new technology, how to use it and what it does. Information diffusion is governed by social contacts and marketing. Epidemic models have been widely applied in curve-fitting exercises (Bass 1986; Mahajan et al. 1990). Supply factors and changes in the environment are usually neglected, or incorporated in a crude way. ${ }^{1}$ Mahajan et al. (1990) identify nine crude assumptions, three of which are:

1. Total market potential of a new product (i.e. final number of adopters) stays constant in time.

\footnotetext{
${ }^{1}$ Nevertheless, starting from Metcalfe (1981), models of diffusion have been proposed incorporating the production capacity growth rate, such as, for instance, by Batten (1987), Amable (1992) and Leoncini (2001).
} 
2. Diffusion of an innovation is independent of all other innovations.

3. The nature of an innovation does not change over time

Although Mahajan et al. and others (for example Lee et al. 2006) mention studies that overcome several assumptions, the models remain one sided in explaining the driving forces of innovation diffusion processes (still spread of information). Other relevant feedback effects, such as progressive improvement of the product (affecting adopter attitudes), remain neglected.

The second type of model is the rational choice model, or threshold model (David 1969; Kemp 1998). In this type of model, economic micro theory is applied based on the assumption of rational behavior: any actor is expected to adopt an innovation the moment it becomes economical to do so. Supply aspects such as the techno-economic characteristics of an innovation can also be incorporated in this type of model (as is being done in Ireland and Stoneman 1982). Learning and social and institutional aspects are typically poorly integrated. The model is mostly applied to the diffusion of production technologies, often using firm size as a critical variate (David 1969; Davies 1979). Bigger companies are expected to adopt earlier because of economies of scale advantages or available capabilities. Bonus (1973) applies a threshold analysis to the diffusion of household durables (cameras, TV sets, automobiles), using income as the critical stimulus (Metcalfe 1981; Amable 1992; Batten 1987; Leoncini 2001).

There has emerged a third type of diffusion model in which technological change is endogenized, this being the evolutionary or 'non-equilibrium' model (in the tradition of Nelson and Winter 1982). Evolutionary approaches have sought to improve rational choice models by including learning of agents, while maintaining an economic focus (Silverberg 1991). The creation of technology and its adoption are seen as mutually dependent-supply depends on demand, and vice versa. Suppliers learn from users and benefit from scale economies, which allow them to sell the improved product at a lower price. Silverberg notes that this black spot of many diffusion studies, decoupling diffusion from further development, dates back to Schumpeter's linear model of progression from invention to innovation to diffusion. He states that realistic concepts should include feedback from diffusion of an innovation towards profitability, relative competitiveness and market shares of the potential developers. The same holds, we argue, for feedback from diffusion to price changes and towards perceived utility for potential adopters.

In their application, evolutionary models have focused on firms and industries and on process innovations related to production efficiency. Windrum and Birchenhall (2005) however, move ahead by presenting a multiagent framework that explicitly models consumers and firms. In their model, the nature and direction of technological innovation is determined by the interaction of heterogeneous consumer preferences and heterogeneous firm knowledge bases at the micro level. Since the two populations exercise a strong selective force on each other, we can speak of a co-evolutionary model. The authors investigate the possibility of technological succession by introducing a 
'technological shock', which is a discrete step towards offering a new feature to the existing set of (service) characteristics. The merit of their approach is the identification of technology as set of characteristics, which makes it a variable, multi-faceted, mediating device between evolving consumers and firms. The approach does not include the social meaning of a technology and imitation of adoption.

In this paper, we aim to extend the co-evolutionary approach to innovation diffusion in a changing social context. To this end, we incorporate elements of the literature of social construction of technology (SCOT; Bijker 1995) into an evolutionary model. We first address the conceptual basis of the model.

\section{Conceptual basis: co-evolution of demand and supply}

\subsection{System concept: extending the co-evolutionary perspective with social context}

In order to make the model fit in cases where technological innovation interacts with a changing social context, we propose to extend the neoSchumpeterian perspectives (Nelson and Winter, Dosi, Metcalfe, Silverberg) with the social construction model of technology of Bijker in a co-evolutionary approach. Whereas the first literature looks at markets and investments by boundedly rational agents operating in a changing competitive landscape, the second literature looks not so much at prices (clearing markets) but at the social context in which technology is created and used. In many cases, this context is not stable, but undergoes change due to the introduction of novelty and the institutional and material adaptations that go with it. Both at the supplier and at the consumer side, various forms of learning take place. These forms of learning are interrelated, in the sense that, at the very beginning, suppliers inform consumers about the innovation, but then suppliers themselves gradually learn how to evaluate demand as the innovation diffuses. Learning entails the availability of new skills and knowledge, new social connotations, changing future expectations, new supplier-user relationships, and changes in the regulatory framework. Consumers, by their different ways of interpreting, using and talking about technologies, further contribute to their social shaping. This is part of what some call the domestication process of products into daily life (Lie and Sørensen 1996). Thus, both the technological hardware and the relevant social context change in a complex process with strong evolutionary traits.

The gradual development of a socio-technical ensemble (or regime) sets out a technological trajectory or path of innovation. A trajectory has its own level of momentum, a combination of velocity of technological progress and the level of diffusion (of use). In the socio-technical landscape, we find novel trajectories beside long established trajectories. The different trajectories (usually) involve different actors, different technologies and business models. 
Geels (2005) worked out the key idea that radical innovations come about through interactions between processes at three levels:

(a) niche-innovations build up internal momentum, through learning processes, price/performance improvements, and support from powerful groups, (b) changes at the landscape level create pressure on the regime and (c) destabilization of the regime creates windows of opportunity for nicheinnovations. Thus, novel technologies (or niches) do not emerge in a vacuum. For example, hybrid-electric vehicles emerge alongside established gasoline and diesel technology. Learning on electric technology takes place alongside progress and learning on ICE technology. In this literature, the term coevolution is increasingly viewed as a foundational concept. Geels elaborates niche-regime dynamics as a multi-level process, with co-evolutionary traits. The definition of co-evolution is, however, not consistent throughout the literature. It tends to be used for any two or more variables that are (partly) dependent on each other, and so becomes a new term for all interaction phenomena. In this paper we follow the stricter definition of Van den Bergh et al. (2006), who state that co-evolution denotes to processes where two variation and selection processes, comprising two or more populations or systems, interact or mutual interfere.

In socio-technical change, there are no actual species that co-evolve. However, demand and supply can be considered as two populations of (attributes of) actors that co-evolve (Saviotti 2005; Windrum and Birchenhall 2005; Dijk and Kemp 2010; Dijk and Yarime 2010; Safarzynska and Van den Bergh 2010). When we speak of demand and supply we thus mean the demand side and supply side. On the supply side, suppliers create technological variety. Of the possible options that emerge, some are selected through purchases in the market to the exclusion of others. On the demand side, we have people of different income and lifestyles, equipped with preferences, beliefs and ways of thinking.

Market price is important, but certainly not the whole story behind supply and demand. Markets are socially embedded (Rip and Kemp 1998), and products are socially constructed (Bijker 1995). Underlying supply and demand, we find socio-economic actors, with ways of interpreting, expectations, capabilities, habits, etc. We therefore consider demand as more than actual sales, as it includes consumer attitudes towards various options. Supply is more than actual production, and involves capabilities, business opportunities, and future expectations towards the various options. The heterogeneity in potential adopters creates a variety of demand. In our scheme, there is present demand and future anticipated demand. Under influence of the latter, suppliers make decisions (select foci) about investment in research and development. By proposing solutions to problems, suppliers are viewed as creating technological variety (see Fig. 1).

The process of co-evolution is thus socially enacted, though not planned by actors. In the case of vehicle engines, the following actors are involved: engine component manufacturers, car manufacturers, users, car repair shops, sales persons, journalists, university researchers and teachers, banks, venture 

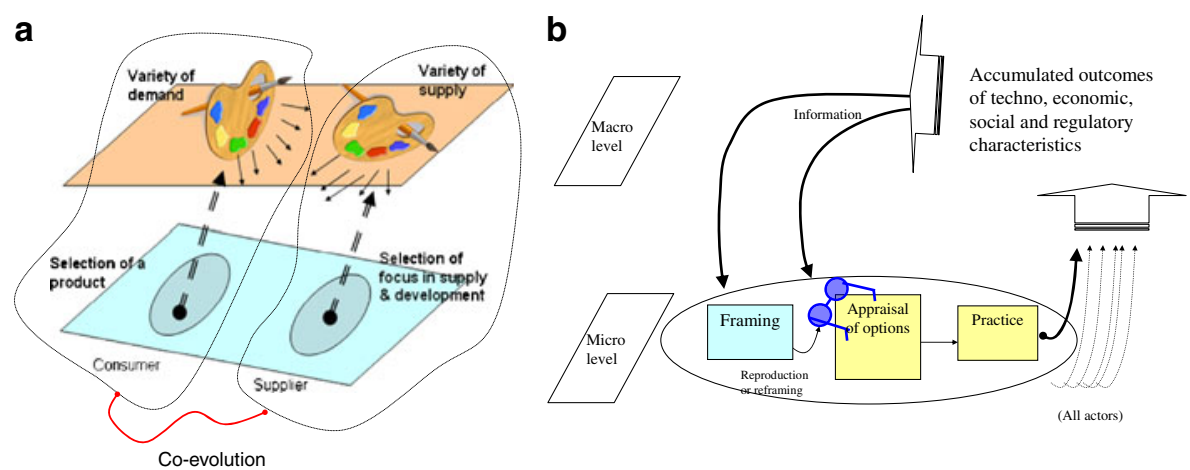

Fig. 1 a Co-evolution of demand and supply as a micro-macro process and $\mathbf{b}$ regime change as a circular process involving two layers

capitalists, shareholders, and policy makers. It is impossible to include all actors in a behavioral model of innovation diffusion. For the purposes of our model, we include three types of actors: car drivers (users of engines), car manufacturers (developers and producers of engines) and policy makers (regulators of the sector and sponsors of research and green products). In our scheme, regulation adapts over time, but is not co-evolving in the same sense as demand and supply. Instead, we regard policymakers, and the regulations they impose, as a force that shapes the co-evolution of supply and demand.

\subsection{Modeling actors: frames and the appraisal of choice options}

In our concept, these actor groups are characterized of having (1) a perspective or frame, which constitutes (2) sense making and appraisal, the outcomes of which influence decisions, and by that (3) behavioral practice. A frame is the structure in which the innovation is described (or interpreted) by an actor. The framing metaphor can be understood as a window or spectacles (worn by the actor group) that filters the total amount of information in a first impression (what it is about and what is important for them), and focuses attention on key elements and aspects within. Thus, framing involves processes of inclusion and exclusion as well as emphasis. In general, this is not a conscious manufacturing process, but is due to unconscious adoption in the course of communicative processes.

Using the example of an alternative engine, say electric propulsion, the user may perceive this as either a green engine, or just another engine, possibly an exciting new engine or something he finds hard to label (he may not give it any thought). For manufacturers, the engine may be perceived as a something that is of interest to their customers, or as a draw for new customers, for which a market is anticipated. For producers, the profitability of an engine (the business case) is likely to be an essential component of the frame. Policy makers, on the other hand, may see the engine as a solution for air pollution 
problems or as something that is interesting from an employment point of view (new jobs).

Frames not only give meaning but also accentuate certain (functional) attributes of the car (engine): maximum speed, power or fuel use, etc. It is well established that goods and services hold symbolic as well as functional value (e.g. Douglas and Isherwood 1979). The groups of users and firms are heterogeneous: users and firms may differ in accentuating various attributes, based on individual agent characteristics (such as preferences and technological capabilities). The frames are unconsciously applied by firms, consumers and policy makers when they deal with various opportunities and problems of vehicles, and in doing so they create an attitude towards the various choice possibilities: e.g. adoption, rejection by users, investment in $\mathrm{R} \& \mathrm{D}$ or product launch by developers. For consumers, we keep track of their receptiveness for each option. Receptiveness is an extended/enriched type of utility, including both functionality attributes, and an attribute of social connotation (which is further elaborated in Section 4). For suppliers, we follow their (current) business opportunity and (future) expectations in the two technologies. These agent attitudes are the starting point for any decision about what to do (how to behave, which will also depend on circumstances such as the need to replace a car, opportunity costs and so on).

\subsection{Driving the dynamics: five feedback loops}

While the previous process takes place on the micro (agent) level, the collective effects create macro patterns, which may be captured by indicators measuring collective outcomes. Examples of such indicators are: total sales of the various options, prices and technological progress of various options. These macro level indicators in turn influence the (micro level) individual agents: it is a circular (micro-macro) process. Similarly, we can distinguish feedback loops at the micro-level, resulting from a direct interaction between the actors involved. Figure 3 visualizes this conception of regime change as a dynamic process involving feedbacks across two layers.

The studies of innovation we reviewed (Dijk and Kemp 2010) have identified various feedback mechanisms during the emergence of a product market or industry. Between the micro- and macro-level we distinguish (see Fig. 3):

- Increasing returns to scale: cost per unit fall as firms take advantage of economies of scale, allowing them profitably to sell products at lower prices, which stimulates sales and further scale economies

- Learning about the market: growing sales lead to better knowledge about the heterogeneity of demand (who prospective buyers are, their willing to pay for specific features, what is valued and less valued), knowledge which may be used for R\&D and new product offerings, which will give rise to better products and more targeted marketing effort that will stimulate sales

- Social construction of meaning: products obtain a social meaning, which will differ across groups; products may become more or less desirable 
because of this. The dynamics may stimulate sales (in the case of positive stories and connotation) or discourage them (in the case of negative stories and meanings)

Alongside these micro-macro processes, there are also micro-micro feedback loops:

- Learning-by-doing: production experiences lead to improved skills and help to discover cost-efficiencies in production, allowing manufacturers to reduce prices and increase sales and production.

- Imitation of use: potential adopters have a tendency to imitate peers (taste formation), and on the supply side, producers may also imitate successful features of competitor products.

The velocity of the loops differs. Some loops are more rapid, such as falling prices in the course of a few years, or the improvement of technological quality of new options. Other loops are slow or discontinuously changing, such as those involving social factors. Further, actor frames are slow or highly discontinuous components. They are shaped by institutional structures, both formal ones, such as governmental regulation, and informal, such as cultural values or personal preferences. Actor frames provide stability to sociotechnical regimes. In our simulation model, the slow change loops are not endogenous (for reasons of simplicity).

We consider the dynamic process, mediated by the feedback loops, as constituting co-evolution of demand and supply of products. In the next section, we make this concept 'tailored' for the case of car engine innovation.

\section{A formal model of car engine innovation}

In this section, we describe the simulation model concisely. For a more detailed description (including equations and parameters), we refer the reader to Appendix 1.

\subsection{Model overview}

The model assumes a limited number of possible innovation trajectories: one related to internal combustion engine (ICE), and one to electric/ hybridelectric $((\mathrm{H}) \mathrm{EV})$ technology. We have two populations of agents: a large group of potential consumers (1000), and a small group of potential suppliers (10 firms). A prospective consumer considers buying a vehicle. He may adopt a vehicle type, or postpone the decision. After adopting a vehicle type, an agent is out of market for 15 time steps (re-purchase period). Then he is receptive again to buying a new vehicle type. Suppliers sell vehicles, invest in $R \& D$, and assess their business opportunities in the two technologies.

Agents are conceptualized by three components: (1) a frame-structure, (2) an evaluation of options, and (3) a decision (e.g. adoption by users; investing 
in $\mathrm{R} \& \mathrm{D}$ or launching products by developers). The two agent groups, users and suppliers, are heterogeneous, and individual agent characteristics are considered (such as preferences and technological capabilities).

In accordance with the conceptual framework, the model has two layers. The micro level contains the characteristics and decisions of agents. The macro level contains aggregate variables, such as total adoption levels, total investment levels, prices, and social connotations, see Fig. 1.

Regulators are considered exogenous in the model, for simplicity. We assume an exogenous regulatory system in place that requires gradual reduction of emissions. We assume that these requirements can be met with both technologies.

\subsection{User frame and supplier frame}

The user frame accentuates certain attributes of the car (engine). Each attribute goes with a certain 'weight' or emphasis. The following attributes are taken into account, see Fig. 2:

- Price $(P)$ of the innovation or 'cost of adoption'

- Perceived functionality $(P F)$ : the direct utility a potential adopter perceives, in comparison to the current situation. The utility depends on technical characteristics of the innovation and functional needs of the individual user

- Social connotation (SC) of an innovation, as defined by cultural peers.

- Environmental impact (EI) of an innovation, with regard to ecological and social impact.

The frame consists of four weights of the four factors: w1 to w4. This actor frame is the basis for the appreciation of the innovation (i), which leads to a certain level of 'receptiveness' ( $R$ ) in the following way:

$$
\mathrm{R}_{i}=\left(\mathrm{w}_{1} \times \mathrm{PF}_{i}+\mathrm{w}_{2} \times \mathrm{SC}_{i}+\mathrm{w}_{3} \times \mathrm{EI}_{i}\right)-\mathrm{w}_{4} \times \mathrm{P}_{i}
$$

Fig. 2 Typical user frame-structure

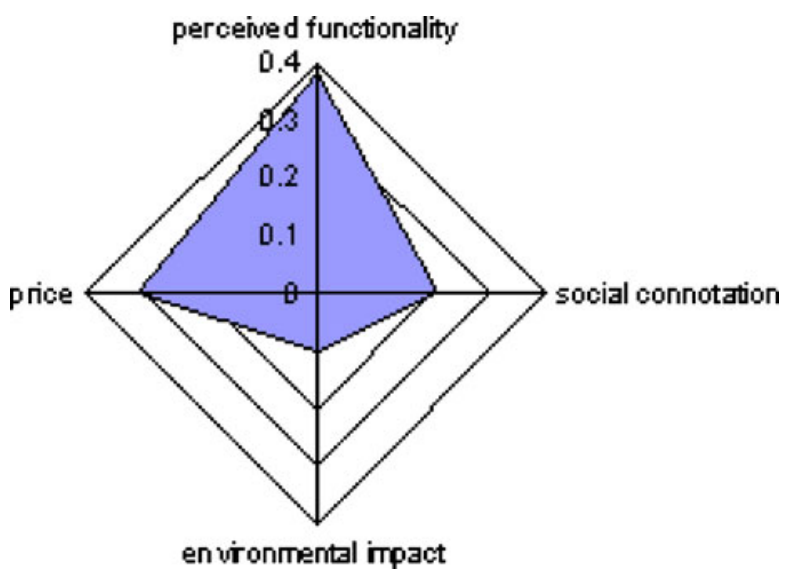


Table 1 Two weight sets representing two consumer groups

\begin{tabular}{lll}
\hline & Frame group 1 $(900 \times)$ & Frame group 2 $(100 \times)$ \\
\hline Weight 1 & 0.75 & 0.4 \\
Weight 2 & 0.3 & 0.3 \\
Weight 3 & 0.1 & 0.5 \\
Weight 4 & 0.2 & 0.2 \\
\hline
\end{tabular}

In other word, psychological and cultural factors of meaning and framing are combined with economic variables such as cost of adoption (indirect utility) and perceived functionality (direct utility). Especially automobiles are acknowledged to provide more than just transportation. They have a symbolic meaning that goes beyond functionality. Receptiveness is an extended/enriched type of utility. Each potential user is characterized by an individual level of receptiveness.

In another paper, we have analyzed consumer frames of car engines in more detail (Dijk 2011). Our estimations here are based on that analysis (see Table 1 and also Appendix 1). We assume a large consumer group for which functional performance is most important, and a small group for which environmental impact is key. For both groups, we take price and social connotation as being of equal importance.

A supplier's frame, on the other hand, is about the business case or business opportunity of a car engine, which is assessed by weighing up expected benefits and expected cost of launching a new vehicle. Supplying firms differ in their precise strength and weakness of capabilities for innovation (cf. the literature on 'core capabilities'), which will drive their expected cost for launching a new product technology. Silverberg (1991) denotes the importance of production quantity for the developing firm, in order to get beyond the break-even point. As long as production investments in a new product-technology have no profitable outlook, a firm will wait before launching the product.

Alongside decisions on launching new products, firms also invest in research and development to enhance their technological capabilities. In our model, their future expectations of demand in the two respective technologies (reflected in their R\&D investments), are driven by (1) the number of successful launching competitors (endogenous in the model), and (2) the (current) level of positive social connotation of a technology (endogenous in the model). ${ }^{2}$ The two components have equal weights.

\subsection{Implementing the feedback loops}

The innovations evolve over time, as does the social environment (connotations). As a consequence of both, agents' attitudes towards the innovation(s) change. Mechanisms of change describe how various factors relate to each

\footnotetext{
${ }^{2}$ We assume that the social connotation of the technologies affects the regulatory pressure for the two technologies (e.g. purchase subsidies, tax benefits). Therefore, the social connotation is an important driver for firm $R \& D$ investments.
} 


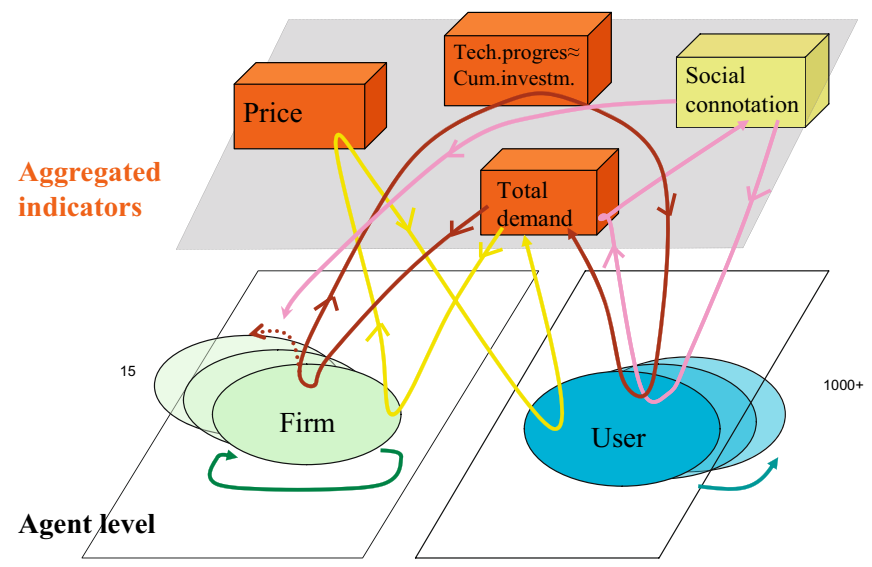

Fig. 3 Five feedback-loops: increasing returns-to-scale (yellow), learning-by-doing (green), imitation of use (blue), learning-from-the-market (brown), and formation of symbolic meaning (pink)

other. Five feedback-loops that have been identified in the literature are implemented in the model. They are described below, and visualized in Fig. 3.

Increasing returns-to-scale and learning-by-doing The increasing returns-toscale mechanism consists of the following sequence: costs per unit fall as firms take advantage of economies of scale, allowing them profitably to sell products at lower prices, which stimulates sales and further scale economies. Costs also fall because of learning-by-doing (workers getting better at what they do). In our model, learning by doing is implemented through decreasing variable costs over time. This accounts for the producers' accumulated experience over time, or by their cumulative output. ${ }^{3}$ Increasing returns-to-scale is implemented through price setting of firms, who divide their fixed and variable costs over their (expected) production volume. When their production volume rises, prices decrease. ${ }^{4}$

Learning-from-the-market Besides learning-by-doing, there is also learningfrom-the-market. Learning-from-the-market refers, on the one hand, to user feedback helping suppliers to improve their products, and, on the other hand, to better ways of using the innovation by the consumers (Rosenberg 1982). Increase of use gives developers insight into customer preferences, which

\footnotetext{
${ }^{3}$ In an ideal case, the decrease of price would be linked only to specific producers (namely, those that have launched), but this was too complex for the current model. Here, the price decrease counts for all producers. Since firms only differ on the level of technological competences, the company with highest technological capabilities (lowest investment cost) will set the market price. ${ }^{4} \mathrm{We}$ assume that the market price of the innovation is the lowest price at which at least one company can still make a profit. Fixed cost accounts for investment in $R \& D$, product engineering and production facilities. The variable cost counts for material and labor of one product.
} 
are obviously heterogeneous. This helps to direct their investments in new product launches, serving a greater range of customers. Because of learningfrom-the-market, we are likely to see greater (perceived) product quality and better matching product variety, both of which will increase perceived functionality from customers. This will lead to a further increase of adoption of the innovation.

This mechanism is implemented as follows. As a first component, capabilities of (all) firms rise when the numbers of consumers rise (even if a firm has not launched a product in that technology). Firms thus learn (directly, i.e. without own R\&D) from the use of products of rivals, which is referred to by some as emulative learning (Windrum and Birchenhall 1998). Second, the increasing number of launching competitors (due to rising consumer sales) will drive up the R\&D investment levels of all firms, which will increase their technological capabilities. As a third and final component, R\&D investments will increase user perceived functionality. This is modeled simply as follows: perceived functionality of an innovation increases with total increasing investment in an innovation. These model assumptions thus reflect the mechanism that user feedback eventually leads to better products.

Formation of symbolic meaning of products Whereas the previous mechanism identified the increase in utilitarian functionality, this subsequent mechanism addresses socio-cultural values that are connected to the product.

The symbolic meaning and appreciation of the product becomes (among others) manifest in stories of market actors (Rosa and Spanjol 2005). When making a speech on a car engine, agents use adjectives or adverbs. By telling stories to each other, social connotation spreads and thus affects receptiveness. Though symbolic meaning and appreciation of a product is a pluralistic phenomenon, ultimately the set of adjectives and adverbs is net positive (adding perceived value to the product), or negative. In the case of a car engine, people may use terms such as 'revolutionary', 'super', 'promising', 'high-tech', 'you want to be seen in this', or, in contrast, terms such as 'bulky', 'weak' or 'dull'.

In our model, the social formation of meaning involves two conflicting stories: a positive one and a negative one. Agents may become included in one of the two respective social constructs. This is implemented by assuming different trends for spreading the stories: after market launch, the number of users included in the positive connotation of a product may grow steadily in time, up to $80 \%$ of the population, while the group with negative connotation stays small. This is an example of the dominance of the idea 'you need to have this'. Similarly, strong growth trends can be assumed for negative stories. Each of the patterns can be chosen as an input to the model, to explore scenarios. (By the way, being included in the construct of a positive story does not mean that an agent in all cases adopts. It is one of five factors in the formation of 'receptiveness'.)

Imitation of use For consumer products, there is a tendency of potential adopters to imitate peers (e.g. Rogers 1995). We treat imitation as a band- 
wagon effect ${ }^{5}$ within the social group (which is the group with whom they share the same frame). In a bandwagon process, individuals do not make the final decision to adopt or reject, but are receptive to social pressure (from others who have already adopted) that spreads through the population (Abrahamson and Rosenkopf 1993). The distribution of receptiveness is heterogeneous, however, so that differences in individual benefits to the innovation result in a higher or lower receptiveness.

A more detailed account of the model can be found in Appendix 1. More than existing models, this model should be suitable to analyze the role of changing social connotation of a product within the co-evolution of demand and supply.

\section{Modeling results}

In this section, we present simulation results of the model described in Section 4, using a simple numeric simulation model. We simulate the coevolution of supply and demand for electric engine cars and diesel engine cars as competing products. The five feedback-loops, which underlie the coevolution of demand and supply, are incorporated.

The model outputs show how two innovation trajectories may co-exist in the sector, as a result of diversity in preferences (i.e. framing) of different consumer groups. We have calibrated the model for the first half of the model run by mimicking what we know about the diffusion of electric and diesel engine passenger cars from 1990 until $2010 .{ }^{6}$ A detailed model analysis is provided in Appendix 2. This analysis suggests that the model is valid for an order-of-magnitude analysis of cause and effect relationships of social connotation with technical and economic factors such as investments, prices, technological progression and adoption.

We present two runs. In the first run, we assume an increasing share of the consumer population becoming included in a positive social construct (i.e. connotation) for $(\mathrm{H}) \mathrm{EVs}$ in the longer run. At the same time, a negative connotation of ICE technology becomes dominant.

In the second run, we assume again a positive connotation for $(\mathrm{H}) \mathrm{EV}$, but now we assume that ICE innovations will also predominantly acquire a positive social connotation $(75 \%)$, see Table 2 .

Obviously, there is much more to tell about other possible runs and lessons or propositions we can draw from this model. Nevertheless, for the sake of

\footnotetext{
${ }^{5}$ An alternative way of incorporating imitation would be to place agents in a spatial structure, where they imitate neighbors.

${ }^{6}$ We match the first half of the model and the period of 1990-2010 in the following way. Some research suggests that the average re-purchase time of new cars is 6.3 years (Boyd 2006), and in the model, we choose 15 steps as the re-purchase period. Therefore, 50 modeling steps represent about 22 years.
} 
Table 2 Input values for the two model runs

\begin{tabular}{llllll}
\hline Parameter & RUN 1 & & RUN 2 & \\
\cline { 2 - 3 } \cline { 5 - 6 } & ICE new & $(\mathrm{H}) \mathrm{EV}$ & & ICE new & $(\mathrm{H}) \mathrm{EV}$ \\
\hline InfP: positive connotation & 0.1 & 0.75 & 0.75 & 0.75 \\
InfN: negative connotation & 0.75 & 0.1 & 0.1 & 0.1 \\
\hline
\end{tabular}

this paper, we will only address the role of social connotation, which we can understand better through the examination of these two runs.

For both, the first half of the run is very similar. It shows new diesel engines being launched in the early 1990s, and electric and hybrid-electric engines in the second half of the 1990s. Also, the new diesel systems diffuse towards $100 \%$ at the expense of the non-direct-injected diesel engines between 2005 and 2010. Further, the diffusion of electric vehicles stagnates after initial launches due to the perceived superiority of diesel technology at that time. In the second half of the model period, the model runs diverge.

In Run 1 (see Fig. 4a-f), we choose the social connotation of HEV to become strongly positive and ICE strongly negative (Fig. 4a). We observe that the market share of (H)EV steadily rises after step 50 (Fig. 4b). In the other graphs, we find explanations for this. For instance, the state of $(\mathrm{H}) \mathrm{EV}$ technology is progressing at a steeper rate than ICE (Fig. 4c). It overtakes

(a) Input: Social Connotation

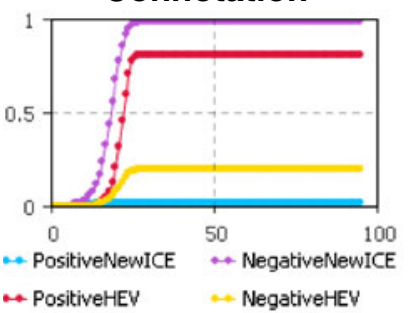

(d) Receptiveness (step 15)

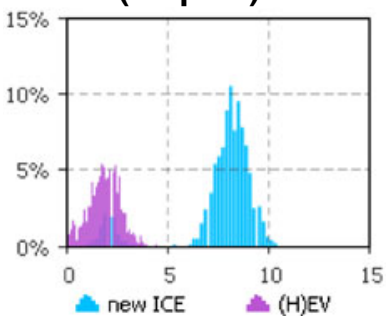

(b) Market shares

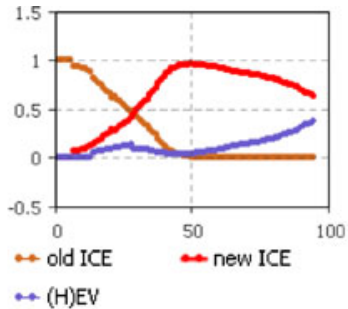

(e) Receptiveness (step 30)

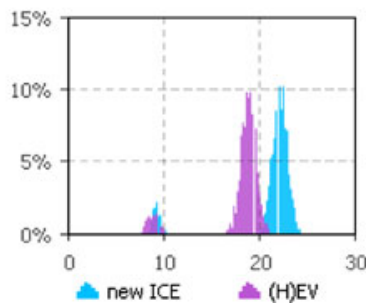

(c)Technological Progress

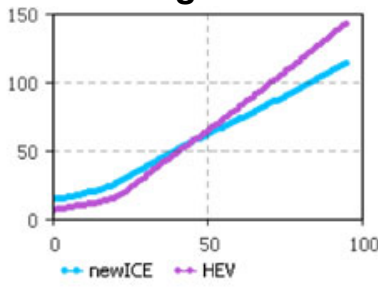

(f) Receptiveness (step 60)

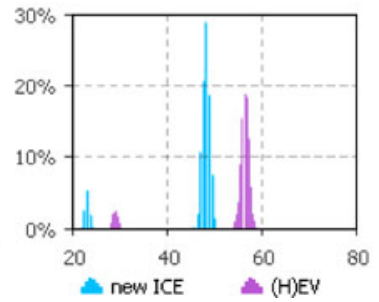

Fig. 4 Model output Run 1. In this run the input is: only HEV acquires a positive Social Connotation, whereas ICE a negative 
ICE at about step 40. As a consequence, for the majority of consumers, receptiveness for HEV overtakes receptiveness for ICE at some point in time. Figure $4 \mathrm{~d}-\mathrm{f}$ give insight into the relative movement of the receptiveness for the two technologies, where the two consumer groups can be clearly distinguished (as the large and the small distribution of the same color). The $\mathrm{x}$-axis depicts the receptiveness level (not time) and each of the three graphs represents a moment in time. The comparison of Fig. 4e-f suggests that receptiveness for HEV for the large consumer group overtakes receptiveness for ICE between steps 30 and 60 (i.e. about step 40). For the smaller consumer group (of environmental consumers), this happened earlier (about step 30).

In Run 2 (see Fig. 5a-f), we choose social connotation of both (H)EV and ICE to become predominantly positive (Fig. 5a). Here we find the market share of $(\mathrm{H}) \mathrm{EV}$ remaining marginal in the longer run (Fig. 5b). The state of ICE technology remains superior to $(\mathrm{H}) \mathrm{EV}$ (Fig. 5c). Consumer receptiveness of ICE remain higher than for ICE, even for the green market niche (see Fig. 5d-f).

In both runs, we find similar price trends. We find the price decreasing because of rising firm capabilities and (after launch also) economies-of-scale. However, we also find that the price rises again when more suppliers launch

(a) Input: Social Connotation

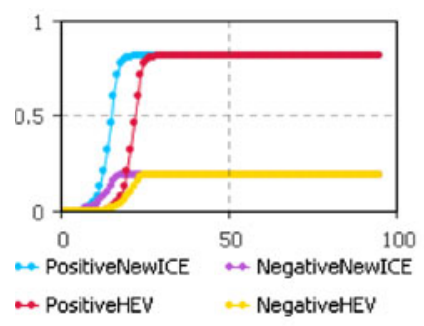

(d) Receptiveness (step 15)

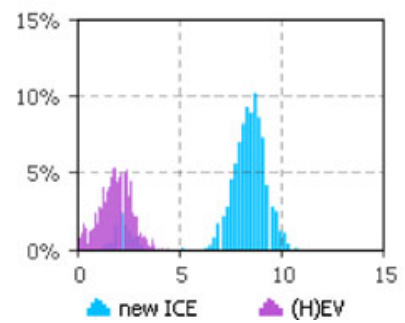

(b) Market shares

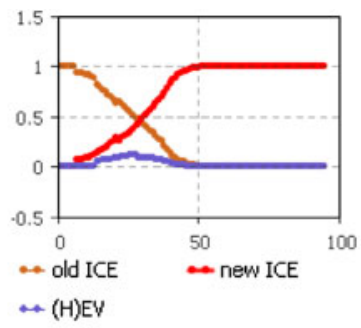

(e) Receptiveness (step 30)

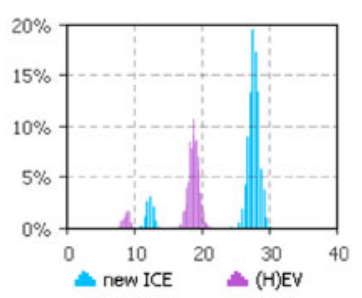

(c) Technological Progress

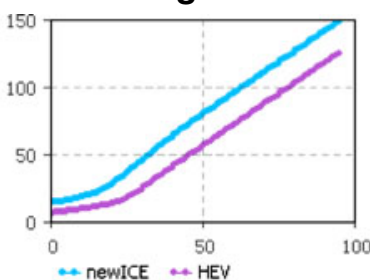

(f) Receptiveness (step 60)

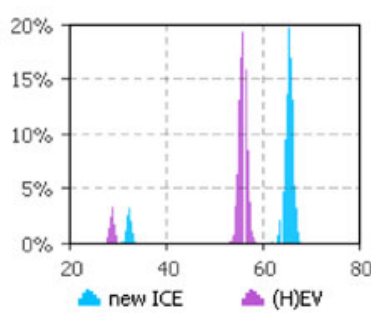

Fig. 5 Model output Run 2. In this run the input is: both HEV and ICE acquire a positive Social Connotation 
vehicles on the market at a time that the market niche is not growing in terms of consumers.

At first glance, this is strange (prices usually decrease during wider diffusion, especially when competition rises), but a closer look suggests that it is caused by a jump in the perceived quality of the product, due to a series of launch investments of firms. In other words, it is not the same product of which the price rises, but is a new generation of the technology. In practice, we also found new generations of DI injection diesels engines (or plug-in hybrids for that matter), which have initially higher prices (together with their higher perceived functionality). Although we can understand why the price trend in the model may jump (at a moment of much investment and technological progression), this is somewhat problematic and needs reconsideration in future applications of the model. Still, for the analysis of the role of social connotation, this discontinuity in the price trend does not seem to be significant. (For example the figure of the market shares shows just a slight unevenness on the moment the price jumps).

Another issue is the relative importance of various learning mechanisms. In the current model, firms learn in various ways (through $\mathrm{R} \& \mathrm{D}$, from market sales (use), from each other), but the output graphs show that their technological capabilities mostly grow from R\&D investments, whereas learning from user levels is a minor effect. (That is the reason why, in run 2, the Technological Progress graphs remain parallel, despite the wider use of ICE.) In general, the relative strength of learning mechanisms and other feedback effects is significant for the model results, whereas practical information to support the choices is hardly available, and therefore it is fairly hard to check whether these are reasonable assumptions.

Lessons learned We draw a few lessons on the role of social connotation in the innovation dynamics from these model runs:

- Initially, the role of social connotation for new technologies is rather weak, since the connotation is poorly defined (right after launch). They only slightly impact R\&D portfolios, and, at the demand side, few consumers adhere to a connotation.

- When more consumers adhere to some social connotation of the new products, a positive connotative will mean an increase in receptiveness for the respective consumer groups (even though, for consumers, social connotation remains less important than perceived functionality).

- More significantly, a rise in positive social connotation will trigger more R\&D investments in the new technology and, after some time, trigger more product launches. (For a negative social connotation, this is the reverse effect.)

At long last, when technological capabilities for the new technology have grown to similar levels as those of the established technology, the social connotation provides the competitive edge, and when the adoption level 
surpasses that of the established technology, it will drive even more technological refinements.

\section{Scenarios for electric engine cars and diesel cars}

In this section, we present plausible but simplified descriptions of two possible socio-technological trajectories. They are narrative scenarios, based on expert knowledge, combined with the insights from the quantitative model simulations. We develop two scenarios, based on the two alternative assumptions on the uncertain formation of social connotation in the future. Before presenting the scenario, we concisely describe the developments between 1990 and 2010.

\subsection{Recent history}

Two innovation trajectories can be distinguished for the case of cleaner vehicles after 1990: the conventional diesel and the gasoline internal combustion engine (ICE) trajectory and a trajectory of electric propulsion (EP). ${ }^{7}$ Two important innovations in ICE are Direct (fuel) Injection (DI) systems and variable valve-timing (VVT). In the EP trajectory, we find innovations such as improved batteries (i.e. lithium-ion batteries), regenerative braking and plugin technology. In the last fifteen years, DI systems diffusion has been rapid. Diffusion in electric vehicle innovations, on the other hand, has been slow. The only success so far is the hybrid-electric Prius car, which has sold 3 million units worldwide since 1997. (See Table 3 for a comparison on sales units in the Netherlands).

Behind these diffusion patterns is a complex phenomenon. The fast diffusion of DI systems and slow diffusion of electric vehicle technologies can be described and explained with the help of the two-layered, co-evolutionary model. Electric propulsion requires new capabilities at the supply side and positive appraisal from consumers. We observe that, while electric vehicles improved, consumers still chose an improved ICE vehicle. This slowed down both the development and diffusion of electric vehicle technology. Up until today, electric vehicles have suffered from two unfavorable characteristics: low autonomy (kilometers per battery charge) and high battery costs. Alongside these techno-economic mechanisms (which have been studied relatively well), a social mechanism played a role. Concerns about the climate enhanced awareness of impact of technologies. Social meaning and the image of new engine types is, however, not an 'instant delivery' phenomenon, but unfolds over time and with level of use. As a consequence, suppliers were initially reluctant to invest (much) in alternative models and capabilities, until they observed changes in actual market launches of competitors, and also in the

\footnotetext{
${ }^{7}$ We discard developments in hydrogen technology here.
} 
Table 3 Yearly sales of diesel cars, battery electric vehicles and hybrid electric vehicles in the Netherlands 1995-2006

Sources: own calculations based on Avere (2008), Bovag (2008), Beise and Rennings (2005)

\begin{tabular}{lrrrl}
\hline & BEV & HEV & DI diesel & Old diesel \\
\hline 1995 & & 0 & 8500 & 76500 \\
1996 & 60 & 0 & 28800 & 61200 \\
1997 & 10 & 0 & 33250 & 61750 \\
1998 & 15 & 0 & 48000 & 52000 \\
1999 & 13 & 0 & 66000 & 54000 \\
2000 & 12 & 0 & 86400 & 33600 \\
2001 & 0 & 50 & 93600 & 26400 \\
2002 & 0 & 63 & 93500 & 16500 \\
2003 & 25 & 17 & 92650 & 16350 \\
2004 & 7 & 1062 & 102000 & 18000 \\
2005 & 0 & 2800 & 104550 & 18450 \\
2006 & 0 & 2800 & 116450 & 20550 \\
\hline
\end{tabular}

effects of positive connotation of EP on tax incentives (etc.) for EP. Only then did more firms give priority to building up EP capabilities. Up to this day, sales levels of EP have been modest.

On this perspective, the future trajectories will be the outcome of the coevolutionary process: suppliers creating capabilities in electric vehicles and ICE in parallel, affected by socio-regulatory pressures, offering both electric vehicles and new ICEs; consumers assessing HEVs on their fuel economy (higher for non-highway drives), prices (higher), image as a car (green, trendy), engine capacity (sufficient, not spectacular), range (similar), engine noise (absent), and, in the future, the possibility of renting batteries and changing them during a long trip. With help of the model runs, we can give more structure to this analysis, and explore various diffusion scenarios.

\subsection{Two scenarios}

Scenario 1: Social popularity triggers functionality boost In scenario 1, we assume an increasing share of the consumer population adhere to a positive social connotation for $(\mathrm{H}) \mathrm{EVs}$, up to $75 \%$ in the longer run, whereas a majority become negative about ICEs.

$1-5$ years-This scenario foresees only a small growth in the adoption of (H)EV in the next 5 years, limited to a group of green consumers. Other than the latter, consumers are hardly interested in buying $(\mathrm{H}) \mathrm{EV}$, since they perceive price/performance levels of $(\mathrm{H}) \mathrm{EV}$ as inferior. Nevertheless, average receptiveness of consumers for $(\mathrm{H}) \mathrm{EV}$ is increasing, and coming closer to those of ICEs. This rise is both driven by increasing perceived functionality, and increasing positive social connotation of $(\mathrm{H}) \mathrm{EV}$ owing to growing concerns about global warming and higher prices for fuel. These stimulate praise for fuel efficient vehicles, which benefits electric engines, which are more efficient to drive. Moreover, electric vehicles benefit from cultural icons (such as Hollywood stars) buying them, giving electric propulsion a positive image (something we are observing at the moment). The positive social connotation provides support for regulatory measures (most notably national tax exemption schemes) that favor battery and hybrid-electric vehicles. These 
stimulations affect firms' R\&D portfolios, which now devote more resources to EP than to ICE.

5-10 years-After 5 years, rising average receptiveness of $(\mathrm{H}) \mathrm{EVs}$ has not led to massive adoption yet, because it was still inferior to that of ICE. Soon after 2015, however, ongoing investments in electric engine technologies bring perceived price/functionality levels at the same level as (H)EV. New generations of $(\mathrm{H}) \mathrm{EVs}$ include Li-ion batteries and Direct Drive in wheel technology. A variety of models with electric engines appears on the market, some minimizing fuel use (plug-in hybrids), others boosting performance. Renting schemes for batteries emerge, making refueling of electric vehicles possible in a few minutes. Continued policy support of (H)EVs brings prices equal to diesels.

Near 2020, the sector passes a bifurcation point, after which adoption of (H)EVs increases steadily. A second consumer group, those for whom price is the most prominent attribute, increasingly chooses electric propulsion. Around 2025 , their sales have increased to $25-35 \%$.

Scenario 2: ICE strikes back In scenario 2 we assume that the social connotation of both $(\mathrm{H}) \mathrm{EV}$ and ICE becomes more predominantly positive.

$1-5$ years-Scenario 2 foresees a small growth in the adoption of $(\mathrm{H}) \mathrm{EV}$ in the next 5 years, similar to scenario 1 , limited to a group of green consumers, and those who benefit from support schemes for EP. Average receptiveness of consumers for $(\mathrm{H}) \mathrm{EV}$ is growing, due to some refinements in EP technology. However, at the same time, diesels are increasingly equipped with particle filters and, within five years, also increasingly with NOx filters. Firms are successful in presenting these diesels as clean, proven technology, at a relative low price. Because of this, national and EU policymakers start treating filtered diesels as environmentally equivalent to hybrids (partly as defensive support for the European automotive industry).

5-10 years-Without special support from tax authorities, hybrid engines stay somewhat more expensive than diesels, in equivalent vehicles. European automotive firms expect higher profitability from diesel in comparison to hybrids, and focus R\&D on the first. Increased availability of (2nd generation) biodiesel is anticipated. Receptiveness of hybrids stays lower than diesels for a large majority of consumers. In this scenario, the growth of $(\mathrm{H}) \mathrm{EV}$ stagnates and tends to fall. By 2020, hybrids have stayed a niche market only, smaller than five percent.

\section{Discussion and conclusion}

In this paper, we explored future scenarios of car engine technology with the support of a simulation model. In addition to previous evolutionary models, this model is instrumental to analyze technological innovation in a changing social context. 
We suggested and offered an explanation as to the way in which an agentbased analysis of innovation diffusion might be formalized, which offers a micro-underpinning of macro patterns, which incorporates feedback loops from macro to micro. The formal model is analytically novel by taking explicit account of actor frames. By attaching weights to various product attributes, different groups of consumers interpret the same product differently: they attach different meaning and value to it. A frame includes attributes of functionality, but also of social connotation. Mediated by various feedback loops, demand and supply co-evolve. Attention is given to the (changing) techno-economic characteristics of the innovation (as an important supply feature), competition between various product offerings, and processes of taste formation (as an important demand feature). With the model as a supporting tool, it becomes possible to explore various possible futures, depending on what mechanism plays a salient role, and the strength thereof.

We presented two scenarios, based on two assumptions regarding the progress of social connotation. For that matter, we do not suggest that formation of social connotation is the most essential mechanism. Performing our history-friendly simulation analysis, we found that it is a factor of importance, though. Trends in social connotation impact the innovation process in the following way:

- Initially, the role of social connotation for new technologies is rather weak, since the connotation is poorly defined (right after launch). They only slightly impact $\mathrm{R} \& \mathrm{D}$ portfolios, and, at the demand side, few consumers adhere to a connotation yet.

- When more consumers adhere to some social connotation of the new products, a positive connotative will mean an increase in receptiveness for the respective consumer groups (even though, for consumers, social connotation remains less important than perceived functionality).

- More significantly, a rise in positive social connotation will trigger more $\mathrm{R} \& \mathrm{D}$ investments in the new technology and, after some time, also more product launches. (For a negative social connotation, this has the reverse effect.)

- At long last, when technological capabilities for the new technology have grown to similar levels as the established technology, the social connotation provides the competitive edge, and adoption levels surpass those of technology with inferior social connotation, driving even more technological refinements.

In this paper, the model has been applied empirically to the case of clean vehicles, where we examine the diffusion of improved internal combustion engine vehicles and the diffusion of (hybrid) electric vehicles, as part of an integrated analysis in which the diffusion of one vehicle is at the expense of the diffusion of the other. The model can be applied in principle to any diffusion process, both retrospectively and prospectively. The model cannot be used for prediction (because diffusion is not a deterministic process and because we lack data on certain variables), but can be used for exploration 
on the basis of proxy data. Especially micro level data (time series of agents' attitudes and frames for evaluation) is rather difficult to obtain. It is also hard to determine the relative strength of the various feedback loops. These should probably be assessed outside the modeling analysis. Perhaps expert opinion can be used for this. Implementing the model with expert opinion in an open fashion allows for the creation of models closer to real world observations. The strength of such a modeling approach is that it combines the structure and scientific underpinnings of analytical modeling with the richness of participatory methods so as to address real complex issues of societal change in a consistent and meaningful way. We recommend this as a topic for future research.

Open Access This article is distributed under the terms of the Creative Commons Attribution Noncommercial License which permits any noncommercial use, distribution, and reproduction in any medium, provided the original author(s) and source are credited.

\section{Appendix 1: Model description}

The model we used in this paper consists of 1000 consumers, 10 firms and three technologies, and a few exogenous factors. We aim to simulate developments after (approximately) 1990, so we initialize for the 1990 situation.

Agent rules

Consumers /users The principal characteristic of a consumer is receptiveness $\mathrm{R}$ for technology i:

$$
\mathrm{R}_{\mathrm{i}}=\left(\mathrm{w}_{1} * \mathrm{PF}_{\mathrm{i}}+\mathrm{w}_{2} * \mathrm{SC}_{\mathrm{i}}-\mathrm{w}_{3} * E I_{\mathrm{i}}\right)-\mathrm{w}_{4} * \mathrm{P}_{\mathrm{i}}
$$

with the variables being Perceived functionality (PF), Social connotation (SC), Environmental impact (EI), and Price (P) of an innovation, and four frame weights of the four factors: $\mathrm{w} 1$ to $\mathrm{w} 4$. There are two sets of weights representing two consumer groups (see Table 4). PF and P are endogenous; SC and EI are exogenous in the model.

\section{Consumers:}

- Initially own a car with an ICE

- Update their receptiveness for each technology [i] in every time step

- Start to consider re-adoption after they have owned a vehicle for at least 15 time steps (i.e. readoption time $=15$ )

Table 4 Two weight sets representing two consumer groups

\begin{tabular}{lll}
\hline & Frame group 1 $(900 \times)$ & Frame group 2 $(100 \times)$ \\
\hline Weight 1 & 0.75 & 0.4 \\
Weight 2 & 0.3 & 0.3 \\
Weight 3 & 0.1 & 0.5 \\
Weight 4 & 0.2 & 0.2 \\
\hline
\end{tabular}


- Consider re-adoption of a vehicle with either an old ICE (i.e. the version at the start of the model), or a refined ICE, or a (hybrid-) electric version

- Select the technology at both the micro level (relative receptiveness level for the three technologies), and the macro level peer pressures (within their consumer group or frame).

This works as follows. A macrolevel (logistic) spread function determines the number of agents (i.e. a threshold) that adopt the technology in that time step (resembling the social imitation pressure for it). The agents at the micro level are ranked for each technology on the basis of their receptiveness for it. When an agent is ranked above the threshold of the time step, it adopts the product. When an agent is above the threshold for more than one product, he adopts the one for which he has the highest receptiveness.

The total group of 1000 consumers consists of two sub-groups with two distinct consumer frames. One group consists of 900 consumers and one of 100 consumers and their respective frame-structure is as follows:

In another paper, we have analyzed consumer frames of car engines in detail (Dijk 2011). Our estimations are based on that analysis. In the analysis, we found that frames change in the course of market development. Nevertheless, in this version of model, for brevity and simplicity, we assume that frames are static, and we have chosen an average of the frames we found for 2000 and 2005. Also, we have simplified the number of consumer group from three to two groups.

Consumers are initialized with a certain level of initial perceived functionality of the two technologies. We set their perceived functionality of (hybrid-) electric vehicles slightly lower than ICE by 1990, applying normal distributions over the group of consumers (with first the standard deviation, then the average):

$$
\begin{gathered}
\text { perceivedFunctionality }[\text { ICE }]=\operatorname{normal}(1,3) ; \\
\text { perceivedFunctionality }[\text { Electric] }=\operatorname{normal}(1,-1) ;
\end{gathered}
$$

Firms /developers The key characteristics of firms are Technological Capabilities (TC) for a technology, and perceived Business Opportunity (BO). Technological capabilities for a technology are initially uniformly distributed over the firms:

$$
\text { techCap }[i]=\text { uniform_discr(min TC, } \operatorname{maxTC}) \text {; }
$$

with minTC a parameter indicating the lowest capability level of a firm of the group, and maxTC as the highest in the group. (See values below in "parameter values'.)

Firms consider launching new ICE versions and electric versions by assessing the business opportunity of the technology.

Business Opportunity (for developer d): $\mathrm{BO}=\mathrm{B}-\mathrm{C}$

with $\mathrm{B}$ as the benefits (that the developer expects after the investment):

$$
\text { benefit [i] = techES } * \text { techPrice; }
$$

with techES the expected sales and techPrice as the price. 
The cost for the developer $\mathrm{C}_{d}$ is composed of two parts: fixed cost (resembling investments in $R \& D$, engineering and production facilities and launch marketing), and variable cost (from material and labor):

$$
\cos t[i]=\text { techFR-techCap }[i]+\text { launchInvest }+(\text { techES } * \text { techVC })
$$

with techVC as the variable cost, techFr as the capabilities of the most advanced firm, and launchInvest is the investments in production facilities and launch marketing.

Firms launch a product as soon as (expected) returns on investments are higher than $10 \%$.

$$
\begin{aligned}
\mathrm{BO}[\mathrm{i}]= & ((\text { benefit }[\mathrm{i}]-\operatorname{cost}[\mathrm{i}]) /(\operatorname{techFR}-\operatorname{techCap}[\mathrm{i}] \\
& + \text { launchInvest })) ; \mathrm{if}(\mathrm{BO}[\mathrm{i}]>\operatorname{targetROI}) \\
& \text { launch }[\mathrm{i}]=\text { true; }
\end{aligned}
$$

with targetROI as the return on investments.

Firms learn:

1. from $R \& D$. The amount they invest in $R \& D$ in a technology is driven by (a) the number of launching competitors (LD), (b) the (current) level of positive social connotation of a technology (SC), which also reflects the socio-regulatory expectation of a technology. The two components have equal weights:

$$
\text { InvestmentRD }[\mathrm{i}]=\operatorname{maxRD} *(\text { techLD }+ \text { techSC }) / 2 \text {; }
$$

with maxRD as the maximum available R\&D budget for a firm in the time step

2. Learning-by-doing: after launch, the variable cost of a technology decrease in time, $1 \%$ in each time step.

3. Learning-from-the-market:

a. Learning-from-Use (LFU): firm capabilities increase with the level use through a logistic function (Mukoyama 2006): learnFromUse[i] $=$ tech $A * \operatorname{maxLFU} *(1-\operatorname{tech} \mathrm{A})$, with total marketshare of technology A as techA and max LFU as a maximum value.

b. Emulative learning: firms reduce their lag in technological capabilities (w.r.t. most advanced firm) through learning from competitors in the market: by $5 \%$ from each launching firm:

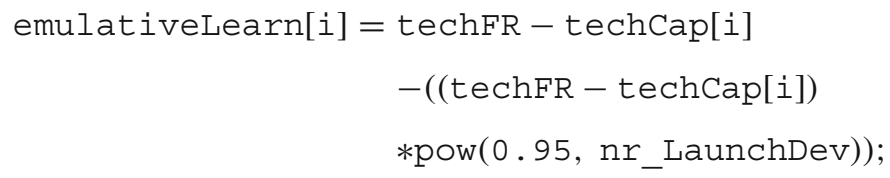


with techFr as the capabilities of the most advanced firm, and nr_LaunchDev as the number of firms that have launched a market vehicles of that technology in the market.

So, firms capabilities for technology [i] increase through:

$$
\begin{aligned}
\operatorname{techCap}[i]= & +(\text { investmentRD }[i]+\text { learnByUse[i] } \\
& + \text { emulativeLearn[i]) }
\end{aligned}
$$

Before and after market launch, each company computes a (virtual) price at which it would still make a profit:

After launch:

$$
\text { price[i] }=(\text { launchInvest } / \text { techEI })+\text { pm } * \text { techVC; }
$$

Or before launch:

$$
\begin{aligned}
\text { price }[i]= & (\text { techFR }- \text { techCap }[i]+\text { launchInvest }) / \text { techEI } \\
& + \text { pm } * \text { techVC; }
\end{aligned}
$$

with techEI as the of expected interest for the technology [i] and techVC as the variable cost of the technology, and pm as the profit margin.

Macro level rules

Price Price develops endogenously: Market price $\mathrm{p}$ of the innovation (at launch) is set by the developer $\mathrm{d}$ which can, at the relatively lowest price, still make a profit. In other words, it is the lowest price of these virtual firm prices:

$$
\text { Price }=\operatorname{MIN}\left(\text { price }_{\mathrm{d}}\right)
$$

This means that the company with highest technological capabilities $T C$ will set the market price.

Aggregate technological progress The firm with highest technological capabilities is regarded as the technological front.

This front moves because of R\&D investments of the firm in every time step, and also through learning from the market. Other firms catch up through emulative learning.

$$
\begin{aligned}
& \text { TechProgression (in a time step) } \\
& \begin{aligned}
= & \text { investment } \mathrm{R}[\mathrm{i}]+\text { learnByUse[i] } \\
& \quad+\text { emulativeLearn[i]) }
\end{aligned}
\end{aligned}
$$

The perceived functionality (PF) of all consumers increases with increasing technological progress of the technology. This is plausible since 
engineers and businessmen at firms try to overcome user-problems as they continue to develop an innovation, from what is already there. So, in one time step:

$$
\mathrm{PF}=\mathrm{PF} \text { (in previous step) + TechProgression; }
$$

Launching developers The number of firms that have launched a market vehicle of that technology in the market is counted every time step (nr_LaunchDev). (For the micro decision to launch or not, see above.)

Aggregate demand and sales The distributions of (consumer) receptiveness for each of the technologies are tracked. In each time step and for each technology the consumers are ranked on the basis of their receptiveness. A macro level (logistic) spread function determines the number of agents (i.e. a threshold) who adopt the technology in that time step (resembling the social imitation pressure for it):

$$
\begin{gathered}
\text { newAdopters[i] }=(1-\text { adoptionLevel[i] }) * \text { adoptionLevel[i]*infA; } \\
\text { adoptionLevel[i]+=newAdopters[i]; }
\end{gathered}
$$

with infA being the level of infectiousness for adoption.

As we described above in the consumer paragraph, actual adoption will only happen if a consumer has owned a previous vehicle for at least 15 time steps, and derived from a combination of the (micro level) receptiveness for the various technologies and the strength of the imitation bandwagon for the technologies.

Expected sales are derived from both the distribution of consumer receptiveness, and the number of other firms expected in the market. A consumer is considered as interested in (i.e. as a potential buyer of) the product when its perceived utility (that is, receptiveness without the price term) is higher than a certain threshold:

$$
\begin{aligned}
& \text { If }\left(\mathrm{w}_{1} * \mathrm{PF}_{i}+\mathrm{w}_{2} * \mathrm{SC}_{i}-\mathrm{w}_{3} * \mathrm{EI}_{i}\right)>\text { AdoptionExp } \\
& \text { expInterest }++
\end{aligned}
$$

By combining the size of the potential market, and the current firms which have launched in this market, the space for a new launching firm is computed and, correspondingly, a number of interested firms (i.e. expected competition). We assume that the market is equally shared between the launching firms. Firms calculate expected sales for each product technology (which they use for computing their business potential) based on the expected consumer interest and expected competition.

$$
\text { expsales = expInterest } /(\text { launchDev }+1) \text {; }
$$


Learning-by-doing After launch, the variable cost of a technology decreases in time (or production levels) by a progress ratio:

$$
\operatorname{varCost} *=\text { learnByDo; }
$$

Social construction of connotation This mechanism is considered exogenous. It is such a socially shaped phenomenon that it does not make sense to link it to techno-economic variables (e.g. investments levels or prices). In the model, it progresses with time. The start of the process for a technology is, however, endogenous, that is, it only starts when sales (and thus use) of the technology are $>0$. Therefore, at the start of the model run, the initial value for new version of ICE and for electric propulsion is 0 , whereas, for the contemporary version of ICE, it is 1 . This means that social connotation is adding value to the product for the consumers who adhere to this connotation.

The formation of social meaning for the new technologies is modelled as follows. Individual consumers become inclined to either the positive connotaion $(+1)$ or the negative connotation $(-1)$ through an epidemic spread function:

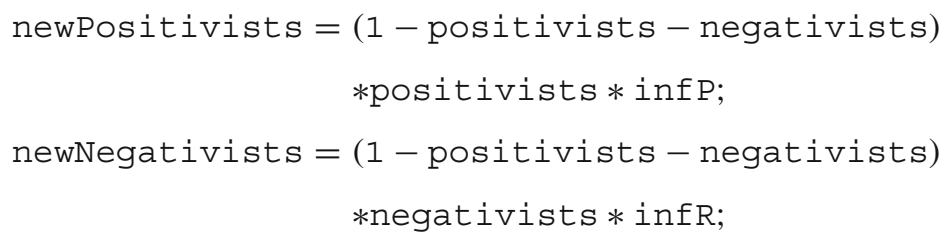

with infP and infR being the level of infectiousness for the two processes. These are the two variables with which the two scenarios are developed. (See Table 5, a reprint of Table 2.)

The connotations spread uniformly over the user population. We assume that the social connotation of the technologies affects the regulatory pressure for the two technologies (e.g. purchase subsidies, tax benefits). Therefore, the social connotation is an important driver for the firm R\&D investments.

Table 5 Input values for the two model runs

\begin{tabular}{llllll}
\hline & \multicolumn{2}{l}{ RUN 1 } & & RUN 2 & \\
\cline { 2 - 3 } \cline { 5 - 6 } & ICE new & $(\mathrm{H}) \mathrm{EV}$ & & ICE new & $(\mathrm{H}) \mathrm{EV}$ \\
\hline InfP & 0.1 & 0.75 & & 0.75 & 0.75 \\
InfN & 0.75 & 0.1 & 0.1 & 0.1 \\
\hline
\end{tabular}


Parameters

\begin{tabular}{|c|c|c|c|}
\hline Symbol & Decsription & Value & Remarks \\
\hline env Impact & $\begin{array}{l}\text { Environmental } \\
\text { impact of } \\
\text { the technologies }\end{array}$ & $\begin{array}{r}{[\mathrm{ICE} \text { new }]=4 ;} \\
{[\text { Electric }]=1 ;} \\
{[\mathrm{ICE} \text { old }]=4 ;}\end{array}$ & $\begin{array}{l}\text { This is an exogenous } \\
\text { parameter. We assume } \\
\text { that the actual } \\
\text { emissions of electric } \\
\text { vehicle are four times } \\
\text { lower that ICE. } \\
\text { Obviously, this depends } \\
\text { to a high degree on } \\
\text { the way electricilty } \\
\text { is generated. }\end{array}$ \\
\hline $\begin{array}{l}\text { (Initial) } \\
\text { minTC } \\
\& \operatorname{maxTC}\end{array}$ & $\begin{array}{l}\text { Technological } \\
\text { capabilities for a } \\
\text { technology are } \\
\text { initially uniformly } \\
\text { distributed over } \\
\text { the firms, these } \\
\text { the boundary } \\
\text { values }\end{array}$ & $\begin{array}{l}\text { For ICE new: } \\
\text { minTC }=6 ; \text { and } \\
\text { maxTC }=14 ; \\
\text { For electric: } \\
\text { minTC }=0 ; \\
\text { and } \operatorname{maxTC}=6 ; \\
\text { For ICE old: } \\
\text { minTC }=15 ; \text { and } \\
\text { maxTC }=20 ;\end{array}$ & $\begin{array}{l}\text { We assume capabilities } \\
\text { for contemporary } \\
\text { ICE technology being } \\
\text { greatest, followed by } \\
\text { calpabilities for } \\
\text { refined ICE, wheras } \\
\text { capabilities for }(\mathrm{H}) \mathrm{EV} \\
\text { are initially lowest. }\end{array}$ \\
\hline (Initial) & Initial perceived & \multicolumn{2}{|c|}{ ICE (old and new): Initially ICE old and } \\
\hline $\mathrm{PF}$ & $\begin{array}{l}\text { Functionality of } \\
\text { the technologies, } \\
\text { which is a normal } \\
\text { distribution over } \\
\text { the group of } \\
\text { consumers }\end{array}$ & $\begin{array}{l}\text { Normal }(1,3) \\
\text { (so standard } \\
\text { deviation } 1 \\
\text { and average } 3) \\
(\mathrm{H}) \mathrm{EV} \text { : } \\
\text { Normal }(1,-1)\end{array}$ & $\begin{array}{l}\text { new are the same. The } \\
\text { average of perceived } \\
\text { functionality of }(\mathrm{H}) \mathrm{EV} \\
\text { around is much lower } \\
\text { than ICE, therefore } \\
\text { minus } 1 \text { compared to } 3 \text {. }\end{array}$ \\
\hline $\max \mathrm{LFU}$ & $\begin{array}{l}\text { Maximum } \\
\text { Learning- } \\
\text { from-Use }\end{array}$ & 1.2 & $\begin{array}{l}\text { Parameter that } \\
\text { inidcates the strenght } \\
\text { of increasing } \\
\text { capabilities from } \\
\text { increasing use. } \\
\text { We calibrated this } \\
\text { in comparison to } \\
\text { learning from R\&D } \\
\text { investments. }\end{array}$ \\
\hline $\mathrm{PM}$ & $\begin{array}{l}\text { Profit margin } \\
\text { applied on to } \\
\text { the variable cost } \\
\text { in the price } \\
\text { computation. }\end{array}$ & 2.5 & \\
\hline
\end{tabular}




\begin{tabular}{|c|c|c|c|}
\hline Symbol & Decsription & Value & Remarks \\
\hline learnByDo & $\begin{array}{l}\text { Parameter that } \\
\text { indicated the } \\
\text { price decraese } \\
\text { in each time step }\end{array}$ & 0.99 & $\begin{array}{l}\text { Ratios for } \\
\text { industrial production } \\
\text { are typically } 80 \% \\
\text { (see Dutton and } \\
\text { Thomas 1984; } \\
\text { Ford model T } \\
\text { was } 87 \% \text { ) } \\
\text { This means: first, } \\
\text { if the first } \\
1000 \text { units cost } \\
100 \text { dollars, the } \\
\text { next } 100 \text { cost } 80 \\
\text { dollars. We apply, } \\
\text { however, the progress } \\
\text { ratio in time (not } \\
\text { in production } \\
\text { quantity). We found } \\
\text { that } 99 \% \text { in each } \\
\text { time step delivers } \\
\text { a similar effect. }\end{array}$ \\
\hline EL & $\begin{array}{l}\text { Emulative } \\
\text { learning from } \\
\text { each launching } \\
\text { firm }\end{array}$ & $5 \%$ & $\begin{array}{l}\text { We assume } \\
\text { that firms reduce } \\
\text { their lag in } \\
\text { technological } \\
\text { capabilities (w.r.t. } \\
\text { most advanced firm) } \\
\text { through learning } \\
\text { from competitors } \\
\text { in the market, } \\
\text { by } 5 \% \text { from each } \\
\text { launching firm }\end{array}$ \\
\hline launchInvest & $\begin{array}{l}\text { Investments } \\
\text { relating to } \\
\text { the market launch } \\
\text { of a technology, } \\
\text { such as production } \\
\text { facilities and } \\
\text { launch marketing }\end{array}$ & 0.3 & $\begin{array}{l}\text { We calibrate } \\
\text { this relative to } \\
\text { R\&D investments }\end{array}$ \\
\hline ROI & $\begin{array}{l}\text { Return on } \\
\text { Invetsments }\end{array}$ & 0.1 & $\begin{array}{l}\text { This means that expected } \\
\text { returns should be } 10 \% \\
\text { higher than investments } \\
\text { before a firm starts } \\
\text { launching. }\end{array}$ \\
\hline
\end{tabular}




\begin{tabular}{|c|c|c|c|}
\hline Symbol & Decsription & Value & Remarks \\
\hline $\operatorname{maxRD}$ & $\begin{array}{l}\text { the maximum } \\
\text { available R\&D } \\
\text { budget for a firm } \\
\text { in the time step }\end{array}$ & 2 & $\begin{array}{l}\text { We calibrate this on } \\
\text { the progression of } \\
\text { the technology. }\end{array}$ \\
\hline varCost & $\begin{array}{l}\text { Variable cost of } \\
\text { the technology }\end{array}$ & $\begin{array}{l}2 \text { (initially, } \\
\text { and will not } \\
\text { become smaller } \\
\text { than } 1 \text { ) }\end{array}$ & $\begin{array}{l}\text { We choose the } \\
\text { same value for } \\
\text { all technologies, } \\
\text { to keep this effect } \\
\text { out of the analysis. }\end{array}$ \\
\hline $\inf A$ & $\begin{array}{l}\text { Infectiousness } \\
\text { level of adoption }\end{array}$ & 0.8 & $\begin{array}{l}\text { This is the strengh } \\
\text { of imitation among } \\
\text { consumers (in their } \\
\text { groups). We calibrate } \\
\text { this for the spread } \\
\text { of direct injected } \\
\text { diesel engines. }\end{array}$ \\
\hline $\begin{array}{l}\text { Re-adoption } \\
\text { period }\end{array}$ & $\begin{array}{l}\text { Average } \\
\text { Ownership period }\end{array}$ & 15 (time steps) & $\begin{array}{l}\text { This is a fairly } \\
\text { random choice, } \\
\text { after which other } \\
\text { parameters are } \\
\text { calibrated. }\end{array}$ \\
\hline AdoptionExp & $\begin{array}{l}\text { A threshold } \\
\text { value for a } \\
\text { consumer being } \\
\text { counted as } \\
\text { 'interested' in the } \\
\text { technology }\end{array}$ & 2.5 & \\
\hline
\end{tabular}

\section{Appendix 2: Model analysis}

Model calibration

We calibrate the model by mimicking the actual data of diffusion of new engines after 1990 in the first half of the model (broadly up to step 50). We match the first half of the model and the period of 1990-2010 in the following way. Some research suggests that the average re-purchase time of new cars is 6.3 years (Boyd 2006) and, in the model, we choose 15 steps as the re-purchase period. Therefore, 50 modeling steps represent about 22 years. Since we take the start of the model as the 1990s, we have calibrated the model (through the initialization of relative firm capabilities and initial perceived functionality of consumers) in order to launch new diesel engines from the beginning of the 1990s onwards (that is, after about four or five time steps), and electric and 

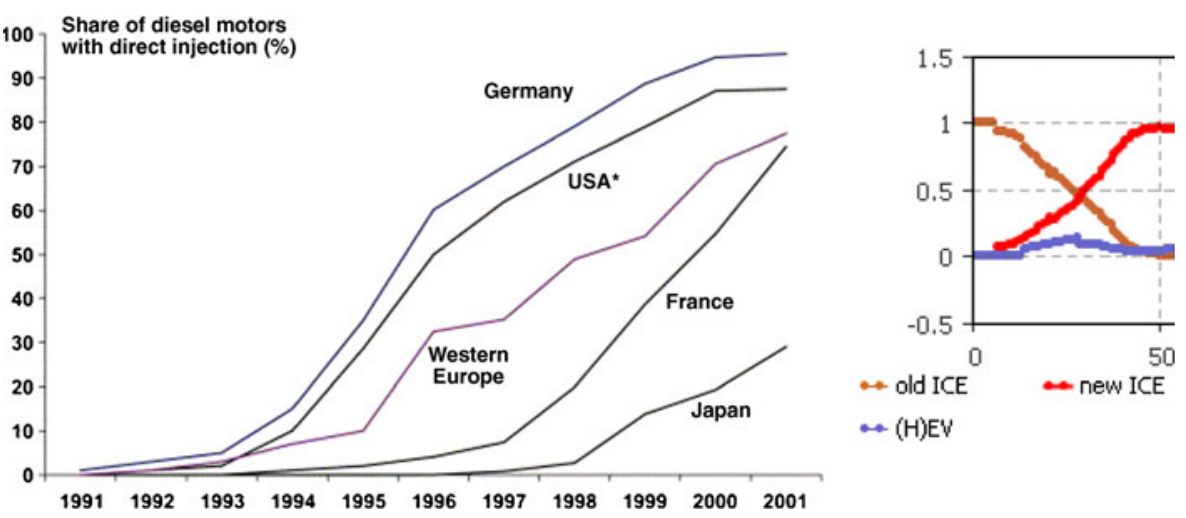

Fig. 6 a Diffusion levels of Direct Injection systems (Source: Beise and Rennings 2005). After 2001 diffusion levels have continued to rise and, on average, we estimate that by 2008-2010 all diesels have direct injection systems. b Model output of Run 1 and 2. The red line resembles diffusion of DI Diesel

hybrid-electric versions from the mid-1990s onwards (i.e. after about 10 or 12 time steps).

Further, we calibrated the model so that diffusion of new diesel engines replaces all old diesel engines at about 2010 (corresponding approximately to step 40 to 45), mainly by tuning the parameter of the logistic imitation function (InfA). This way we mimic the actual data of diffusion of new diesel engines on the world market and of (hybrid-) electric vehicles, which will have gradually grown to a market share of about $3.5 \%$ worldwide by 2010 (see Fig. 6).

Sensitivity analysis

In Section 5, we discussed the results of the model, where we focused on the role of social connotation for the development of market shares, by comparing two runs. Here we assess how other parameters may have a similar effect on market shares. We vary a few key parameters with $+/-25$ to $50 \%$ and observe
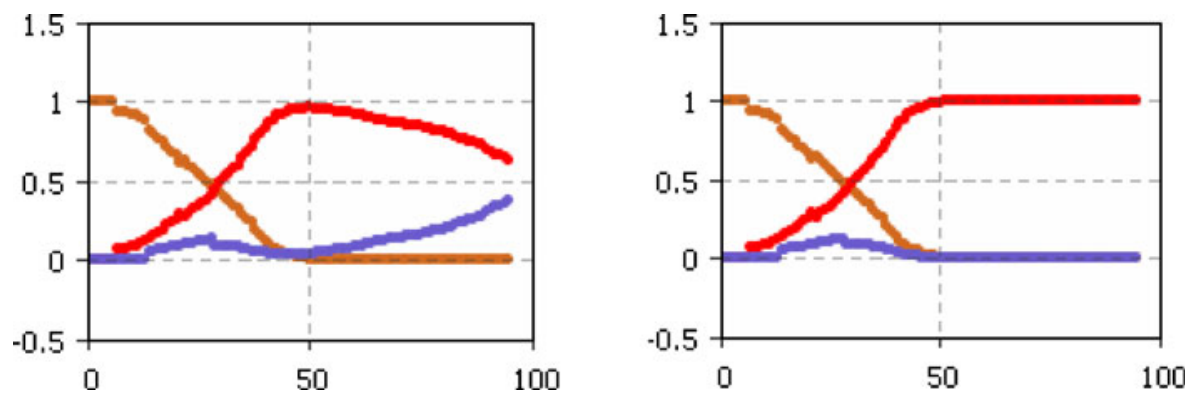

Fig. 7 Market shares in the calibrated model in run 1 and 2 
the impact on the output values, i.e. on the market share trends. As a starting point, we take scenario run 1 (see Fig. 7 left).

\section{Consumer frame weights}

Here we vary with the weight of Perceived Functionality in the frame of the 900 members of consumer group 1.

So, if functionality becomes significantly less important for the largest group of consumers (those who value functionality most), the market share of $(\mathrm{H}) \mathrm{EVs}$ will start to rise much earlier and more strongly (Fig. 8, left). This makes sense, since inferior appreciation for the functionality of $(\mathrm{H}) \mathrm{EVs}$ is an important reason it takes so much time to diffuse: it takes time for firms to build up their capabilities. Alternatively, an even higher weight of perceived functionality does not have much effect (see Fig. 8, right).

\section{Readoption period}

Here we vary with the readoption period from 15 time steps to 10 and 20 .

We find that when consumers more quickly buy a new vehicle (readoption $=$ 10, Fig. 9 left), the slope of diffusion of the innovation increases. However, it does not so much affect the relative investment levels of firms, and therefore (H)EV still overtakes ICE in terms of perceived functionality by around time step 50. Subsequently, the diffusion slope of $(\mathrm{H}) \mathrm{EV}$ is steeper as well.

When consumers are slower in replacing their vehicle, we find the opposite effect. All in all, the model is fairly sensitive for variations in readoption time, which is reasonable regarding the actual market developments.
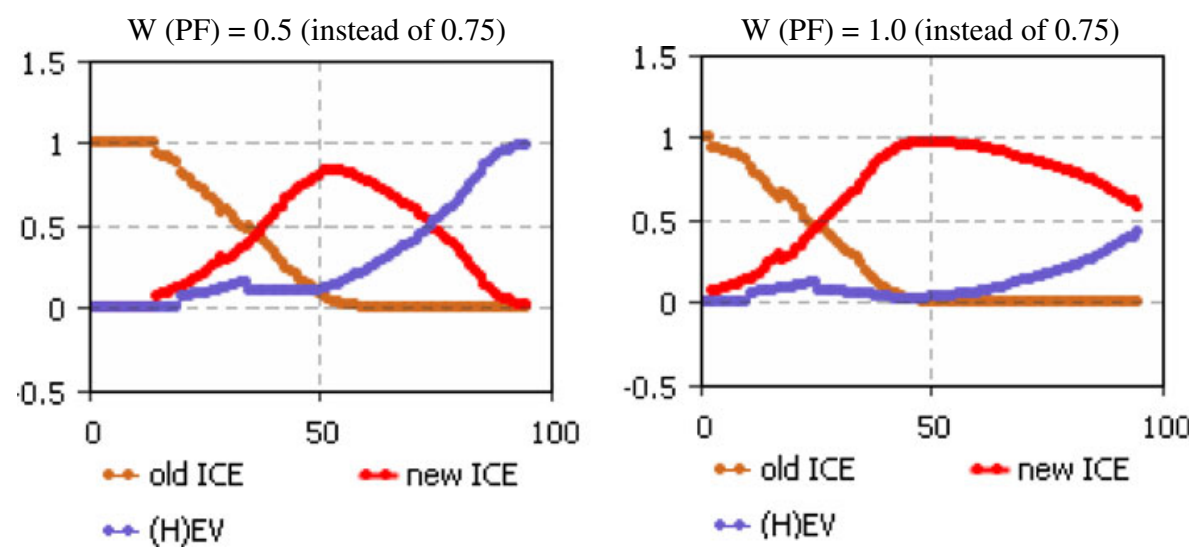

Fig. 8 Market shares in the case of deviating values for weight of PF 

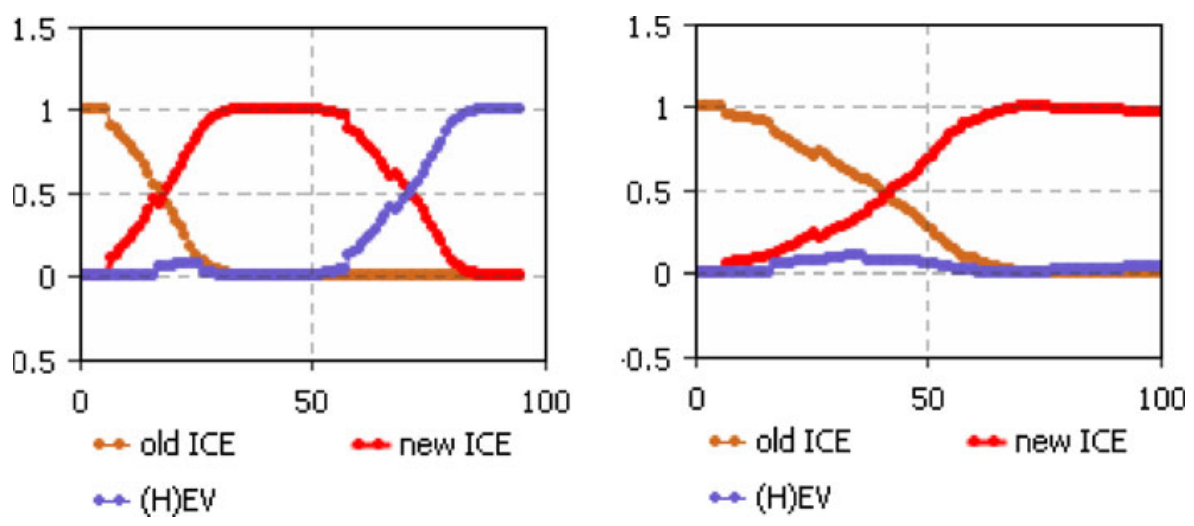

Fig. 9 Market shares in the case of deviating values for readoption time

\section{Maximum $R \& D$ per step}

Here we vary with the maximum R\&D budget available at each firm from 2 to 3 and 1.

When the maximum $R \& D$ budget is 3 instead of 2, the market share of (H)EV rises slightly more in the second phase of the run (see Fig. 10 left). Total investments in $(\mathrm{H}) \mathrm{EV}$ accumulate faster, and perceived functionality overtakes that of ICE at a slightly earlier moment, which makes the sensitivity reasonable. Alternatively, when the RD budget is 1 , we find precisely the opposite (Fig. 10, right). The progression of $(\mathrm{H}) \mathrm{EV}$ is still on its way to overtake ICE, but the slope is lower here, and therefore it takes more time to pass ICE (and, therefore, adoption of $(\mathrm{H}) \mathrm{EV}$ only starts growing after 100 time steps, outside the plot).
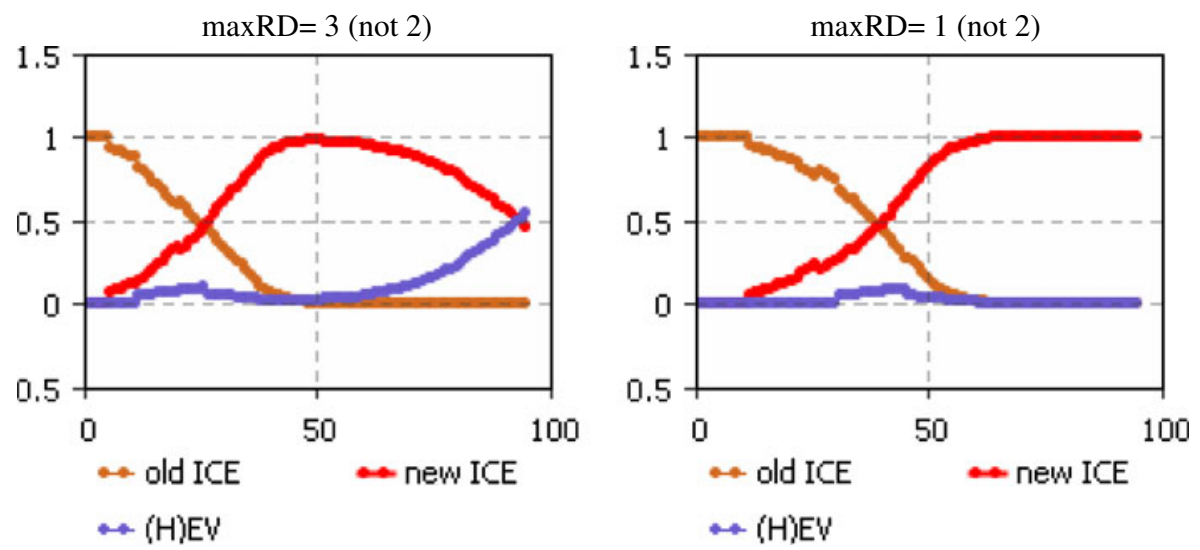

Fig. 10 Market shares in the case of deviating values for maxRD 


\section{Conclusions}

This model analysis shows that the model is fairly sensitive for many more parameters than just social connotation. This is not surprising, since indeed many factors play a role in innovation dynamics, as our conceptual model has proposed. The formation of social connotation is, however, one of the most uncertain, intangible factors in this process; much more than, for instance, the average re-adoption time or the maximum R\&D level. Therefore, it was reasonable to base the two model runs and the respective scenarios on this variable of social connotation.

All in all, we find that the model gives a sufficient 'order-of-magnitude' indication of cause-and-effect relationships of social connotation with investments, prices, technological progression and adoption. There is much more to tell about other possible runs and lessons or propositions we can draw from this model. We recommend other interesting applications of this model, such as the role of changing consumer frames, as a topic for future research.

\section{References}

Abrahamson E, Rosenkopf L (1993) Institutional and competitive bandwagons: using mathematical modeling as a tool to explore innovation diffusion. Acad Manage Rev 18(3):487-517

Amable B (1992) Competition among techniques in the presence of increasing returns to scale. J Evol Econ 2(2):147-158

Avere (2008) EVs today. Brussels, Belgium. www.avere.org. Retrieved Sept 2008

Bass FM (1969) A New product growth model for consumer durables. Manag Sci 15:215-227

Bass FM (1986) The adoption of a marketing model. In: Mahajan V, Wind J (eds) Innovation diffusion of new product acceptance. Ballinger, Cambridge

Batten D (1987) The balanced path of economic development: a fable for growth merchants. In: Batten D, Casti J, Johansson B (eds) Economic evolution and economic adjustment. Springer, Berlin/ Heidelberg

Beise M, Rennings K (2005) Lead markets and regulation: a framework for analyzing the international diffusion of environmental innovations. Ecol Econ 52(1):5-17

Bijker W (1995) Of bicycles bakelites and bulbs: toward a theory of sociotechnical change. MIT, Cambridge

Bonus H (1973) Quasi-Engel curves, diffusion, and the ownership of major consumer durables. J Polit Econ 81:655-677

Bovag (2008) Auto Registraties. Car registrations. Bunnik, The Netherlands. www.bovag.nl. Retrieved Sept 2008

Boyd T (2006) Report on demographic and consumption behaviors of USMS members. USMS, Londonderry NH

David PA (1969) A contribution to the theory of diffusion. Stanford Research Memorandum 71. Stanford Centre for Research in Economic Growth

Davies S (1979) The diffusion of process innovations. Cambridge University Press, Cambridge

Dijk M (2011) Technological frames of car engines. Technol Soc 33:165-180

Dijk M, Kemp R (2010) A framework for understanding product market innovation paths emergence of hybrid vehicles as an example. Int J Automot Technol Manag 10(1)

Dijk M, Yarime M (2010) The emergence of hybrid-electric cars: innovation path creation through co-evolution of supply and demand. Technol Forecast Soc Change 77(8):1371-1390

Douglas M, Isherwood B (1979) The world of goods. Basic Books, New York

Dutton JM, Thomas A (1984) Treating progress functions as a managerial opportunity. Acad Manage Rev 9(2):235-247 
Geels F (2005) Processes and patterns in transitions and system innovations: refining the coevolutionary multi-level perspective. Technol Forecast Soc Change 72(6):681-696

Heffner RR, Turrentine TS et al (2006) A primer on automobile semiotics. ITS working paper 06-01. ITS, UC Davis, Davis

Ireland N, Stoneman P (1982) The role of supply factors in the diffusion of new process innovations. Econ J

Kemp R (1998) The diffusion of biological waste-water treatment plants in the Dutch food and beverage industry. Environ Resour Econ 12(1):113-136

Lee J, Cho Y et al (2006) Forecasting future demand for large-screen television sets using conjoint analysis with diffusion model. Technol Forecast Soc Change 73(4):362-376

Leoncini R (2001) Segmentation and increasing returns in the evolutionary dynamics of competing techniques. Metroeconomica 52(2):217-237

Lie M, Sørensen KH (1996) Making technology our own?: domesticating technology into everyday life. Scandinavian University Press, Oslo

Mahajan V, Muller E et al (1990) New product diffusion models in marketing: a review and direction for research. J Mark 54:1-26

Metcalfe S (1981) Impulse and diffusion in the study of technical change. Futures 13(5):347-359

Mukoyama T (2006) Rosenberg's "learning by using" and technology diffusion. J Econ Behav Organ 61(1):123-144

Nelson RR, Winter S (1982) An evolutionary theory of economic change. Harvard University Press, Cambridge

Rip A, Kemp R (1998) Technological change. In: Rayner S, Malone EL (eds) Human choice and climate change, vol 2. Battelle Press, Columbus, OH, pp 327-399

Rogers EM (1995) Diffusion of innovation. Free Press, New York

Rosa JA, Spanjol J (2005) Micro-level product-market dynamics: shared knowledge and its relationship to market development. J Acad Mark Sci 33(2):197-216

Rosenberg N (1982) Inside the black box: technology and economics. Cambridge University Press, Cambridge

Safarzynska K, Van den Bergh JCJM (2010) Demand-supply coevolution with multiple increasing returns: policy analysis for unlocking and system transitions. Technol Forecast Soc Change 77:297-317

Saviotti PP (2005) On the co-evolution of technologies and institutions. In: Weber M, Hemmelskamp J (eds) Towards environmental innovation systems. Springer, Berlin

Silverberg G (1991) Adoption and diffusion of technology as a collective evolutionary process. In: Grubler A, Nakicenovic N (eds) Diffusion of technologies and social behavior. SpringerVerlag, Berlin, pp 11-22

Van den Bergh JCJM, Faber A et al (2006) Survival of the greenest: evolutionary economics and policies for energy innovation. Environ Sci 3(1):57-71

Windrum P, Birchenhall C (1998) Is life cycle theory a special case? Dominant designs and the emergence of market niches through coevolutionary-learning. Struct Chang Econ Dyn 9: 109-134

Windrum P, Birchenhall C (2005) Structural change in the presence of network externalities: a co-evolutionary model of technological successions. J Evol Econ 12(2):123-148

Windrum P, Ciarli T et al (2009a) Consumer heterogeneity and the development of environmentally friendly technologies. Technol Forecast Soc Change 76(4):533-551

Windrum P, Ciarli T et al (2009b) Environmental impact, quality, and price: consumer trade-offs and the development of environmentally friendly technologies. Technol Forecast Soc Change 76(4):552-566 